\title{
Harnessing Chalcogen-bonding Interactions To Establish Conforma- tional Control in Dirhodium(II) Paddlewheel Complexes
}

\author{
Takuya Murai, ${ }^{+}$Wenjie Lu, ${ }^{\ddagger}$ Toshifumi Kuribayashi, ${ }^{\ddagger}$ Kazuhiro Morisaki, ${ }^{\ddagger}$ Yoshihiro Ueda, ${ }^{\ddagger}$ Shohei Hamada, \\ Takahiro Sasamori, ${ }^{\S}$ Norihiro Tokitoh, ${ }^{\neq}$Takeo Kawabata, ${ }^{\ddagger}$ and Takumi Furuta ${ }^{*,+}$ \\ ${ }^{\dagger}$ Department of Pharmaceutical Chemistry, Kyoto Pharmaceutical University, Yamashina-ku, Kyoto 607-8414, Japan \\ ${ }^{\ddagger}$ Institute for Chemical Research, Kyoto University, Uji, Kyoto 611-0011, Japan \\ ${ }^{s}$ Graduate School of Natural Sciences, Nagoya City University, Mizuho-ku, Nagoya, Aichi 467-8501, Japan \\ Paddlewheel complex, Chalcogen bond, Intramolecular C-H insertion, Axially chiral amino acid, $\gamma$-Lactone
}

\begin{abstract}
Novel well-defined $D_{2}$-symmetric dirhodium(II) carboxylate complexes that bear axially chiral binaphthothiophene $\delta$-amino acid derivatives have been developed. Conformational control was achieved through chalcogen-bonding interactions between sulfur and oxygen atoms in each ligand, providing well-defined and uniform asymmetric environments around the catalytically active $\mathrm{Rh}$ (II) centers. These structural properties render such complexes excellent catalysts for the inside-type asymmetric intramolecular $\mathrm{C}-\mathrm{H}$ insertion into $\alpha$-aryl- $\alpha$-diazoacetates to yield a variety of cis- $\alpha, \beta$-diaryl $\gamma$-lactones, as well as the corresponding trans-isomers through epimerization, in high diastereo- and enantioselectivities. Short total syntheses of the naturally occurring $\gamma$-lactones cinnamomumolide, cinncassin

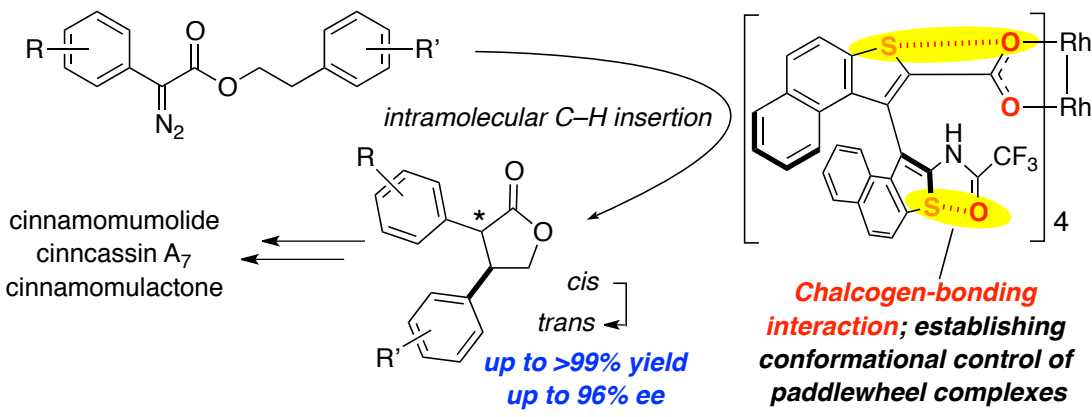
$\mathrm{A}_{7}$, and cinnamomulactone were also accomplished using this conformationally controlled catalyst.
\end{abstract}

\section{INTRODUCTION}

Chiral dirhodium(II) paddlewheel complexes are highly valuable catalysts for stereoselective transformations including insertion reactions in $\mathrm{X}-\mathrm{H}$ bonds $(\mathrm{X}=\mathrm{C}, \mathrm{N}, \mathrm{O}$, etc.) (Figure $1 \mathrm{~A})$ as well as the stereoselective cyclopropanation of unsaturated $\mathrm{C}-\mathrm{C}$ bonds through the decomposition of diazo compounds. ${ }^{1}$ Some of the most frequently employed chiral dirhodium(II) paddlewheel catalysts are dirhodium(II) carboxylate complexes that bear chiral carboxylate groups as paddlewheel ligands.

The construction of a defined asymmetric environment around the catalytically active center is crucial for the development of potential asymmetric catalysts. However, the construction of defined asymmetric environments can be very difficult, especially in the case of catalysts with rotatable bonds near the catalytically active center. Dirhodium(II) carboxylate complexes represent typical examples of catalysts that suffer from undesirable conformational flexibility around the rotatable $\mathrm{C}-\mathrm{C}$ bond of the carboxylate groups tethered to $\mathrm{Rh}(\mathrm{II})$ (Figure 1B). Their conformational flexibility often complicates the construction of defined chiral environments around the upper (Rh1) and lower (Rh2) rhodium atoms, both of which act as catalytically active centers; however, it also enables the construction of diverse and interchangeable structures with different molecular symmetry. Specifically, $C_{1^{-}}, C_{2^{-}}, C_{4^{-}}$, and $D_{2}$-symmetric structures with up-up-up-down, up-up-down-down, all-up, and updown-up-down ligand arrangements relative to the plane of the rhodium carboxylate moieties, respectively, can be formed (Figure 1B). ${ }^{2}$ The presence of uniform chiral environments around the Rh1 and Rh2 centers is particularly important in $C_{2}$ (up-up-down-down)and $D_{2}$ (up-down-up-down)-symmetric catalysts, as inequivalent chiral environments will produce products with non-uniform optical purity. Therefore, an important issue in the development of potential dirhodium(II) carboxylate catalysts is establishing control over the conformational flexibility of the carboxylate ligands around the $\mathrm{C}-\mathrm{C}$ single bond.

We envisioned that the introduction of an interaction that fixes one conformation of the rotatable carboxylate $\mathrm{C}-\mathrm{C}$ bond could provide a dirhodium(II) complex with relatively rigid and uniform chiral environments around the Rh1 and Rh2 centers.

We have previously reported the synthesis of axially chiral binaphthyl $\delta$-amino acid $(S)$-1 and its $N$-protected derivatives (Figure 1C), ${ }^{3}$ as well as their application as chiral carboxylate ligands in dirhodium(II) carboxylate catalyst $2 \mathrm{a}$ (Figure 2C). ${ }^{4}$ Later, we extended these studies to prepare the binaphthothiophene $\delta$-amino acid $(S)$-3, which contains sulfur atoms in its fused $\pi$-system, from binaphthothiophene dicarboxylic acid $(S)-4$ (Figure 1C)., 
(A)

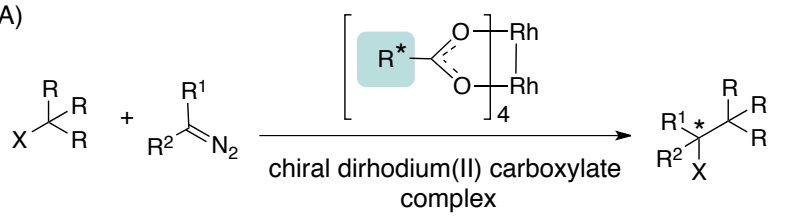

(B)
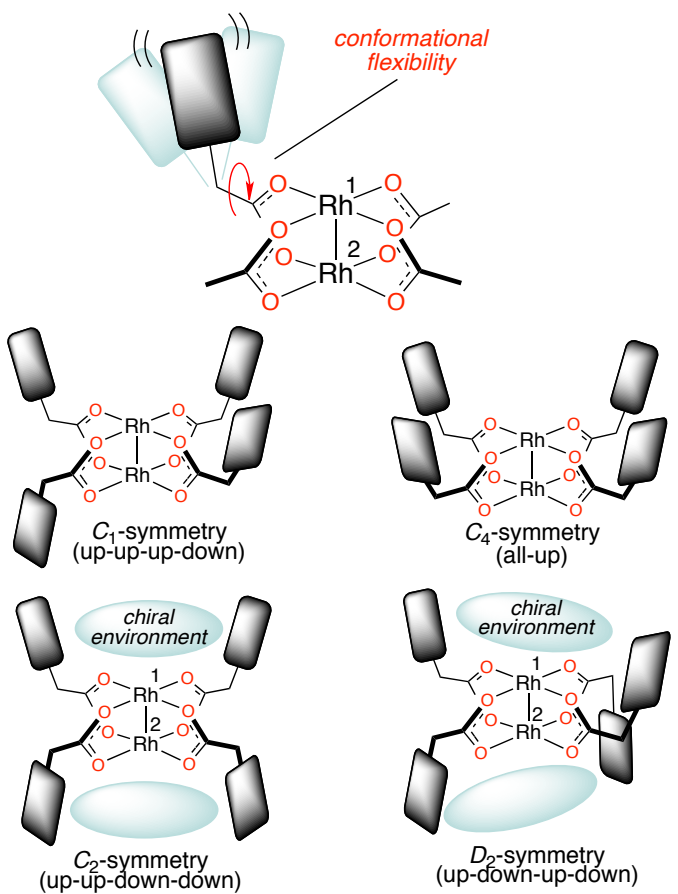

(C)
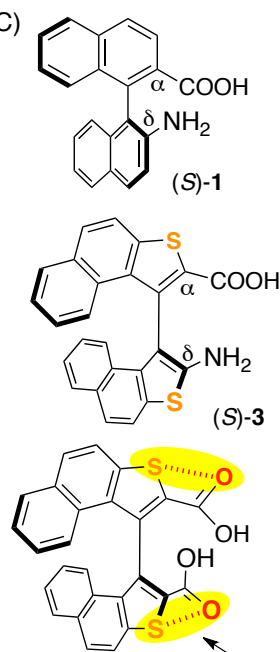

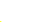

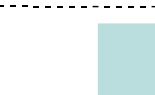

(D) Catalyst design
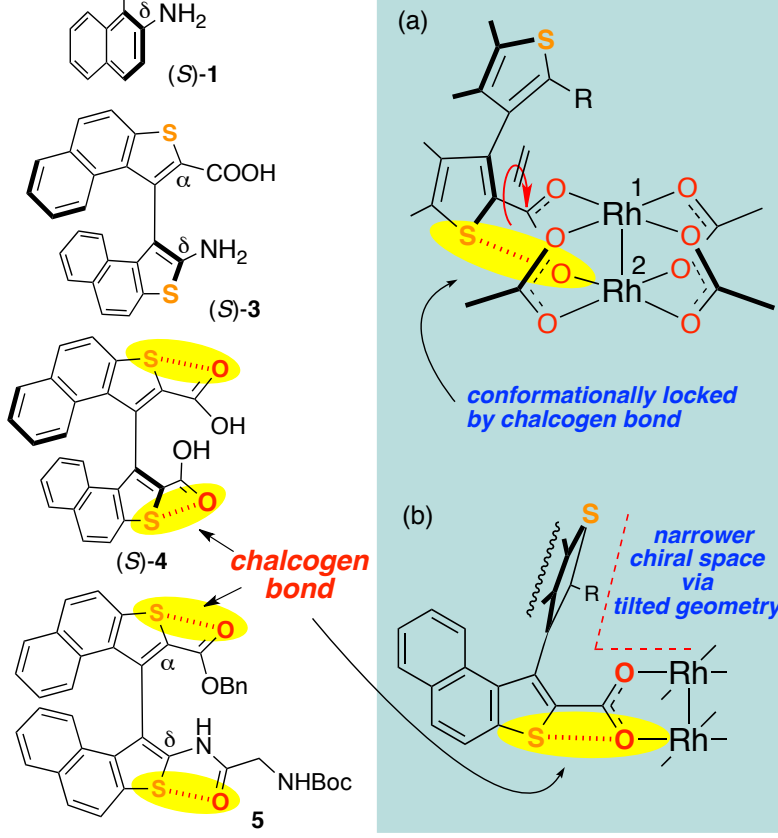

(b)

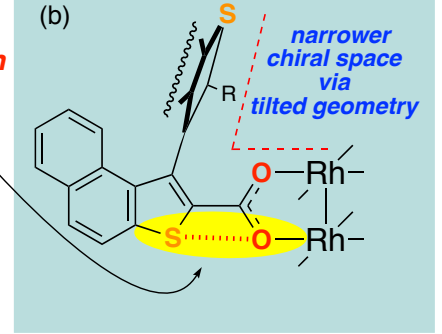

Figure 1. (A) C-X bond insertion reaction catalyzed by a dirhodium(II) carboxylate complex. (B) Conformational flexibility and ligand arrangement in dirhodium(II) carboxylate complexes. (C) Axially chiral binaphthyl and binaphthothiophene $\delta$-amino acids and their chalcogenbond-containing derivatives. (D) Schematic illustration of the concept for the design of the catalyst used in this study.
Furthermore, racemic 3 was transformed into the corresponding amide derivative 5. ${ }^{6}$ Single-crystal X-ray diffraction analyses of $(S)-4$ and 5 revealed chalcogen bonds (.. .0 interactions) between the oxygen atom of the carbonyl group and the sulfur atom of the naphthothiophene ring, which resulted in a co-planar conformation.

Chalcogen bonding has been recognized as a non-covalent interaction that plays a role in determining the conformation of pharmaceuticals and organic materials. ${ }^{7}$ Recently, this interaction has also received attention as a driving force in organocatalysis ${ }^{8}$ as well as an attractive interaction in supramolecular assembly. ${ }^{9}$ We envisaged that the chalcogen-bonding interactions found in $(S)-4$ and 5 could be used to lock the conformation of the carboxylate $\mathrm{C}-\mathrm{C}$ bonds to fix the stereostructure of dirhodium(II) complexes (Figure $1 \mathrm{D}(\mathrm{a})) .{ }^{10}$ Furthermore, this conformational restriction would result in a tilt of the other aromatic ring system of the biaryl ligand toward the inside of the complex to give a narrow and well-defined chiral space near the catalytically active Rh centers (Figure $1 \mathrm{D}(\mathrm{b})$ ). Such chiral environments can be expected to result in good asymmetric induction.

Asymmetric intramolecular $\mathrm{C}-\mathrm{H}$ insertion of $\alpha$-diazoacetates has been investigated as a powerful synthetic tool for constructing a variety of chiral cyclic compounds. These reactions can be classified into two categories based on the type of cyclization that occurs. The first category comprises cyclizations that furnish products in which the ester group is located outside the cyclic system (Figure 2A). In the second category, the ester group is incorporated into the cyclic system as a constituent moiety to afford the corresponding lactone (Figures $2 \mathrm{~B}$ and $2 \mathrm{C}$ ). In this paper, these types of cyclizations are referred to as outside- and inside-type cyclizations, respectively.

Although many highly stereoselective outside-type cyclizations have been reported, ${ }^{11}$ examples of inside-type cyclizations with high enantio- and diastereoselectivities are limited, especially those employing $\alpha$-aryl- $\alpha$-diazoester substrates. ${ }^{12}$ The highly enantio- and diastereoselective inside-type $\mathrm{C}-\mathrm{H}$ insertion reaction of $\mathbf{6}$ to give $\alpha, \beta$ diaryl $\beta$-lactone 7 has been reported by Davies and co-workers as an exceptional example; however, a trifluoromethyl or halogen group at the ortho-position of the $\alpha$-aryl group was required to ensure satisfactory levels of stereoselectivity. ${ }^{13} \mathrm{We}$ have also examined the stereoselective inside-type $\mathrm{C}-\mathrm{H}$ insertion reaction of 3-butenyl $\alpha$-aryl- $\alpha$ diazoacetates 8 catalyzed by 2 a to give $\alpha$-aryl- $\beta$-substituted $\gamma$-lactones 9 (Figure $2 \mathrm{C}$ ). ${ }^{4}$ However, the obtained levels of enantio- and diastereoselectivities were unsatisfactory.

Although this initial attempt using $2 \mathbf{a}$ was unsatisfactory, the asymmetric construction of $\alpha$-aryl $\beta$-substituted $\gamma$-lactones continued to attract us, because this type of lactone is frequently found as the core structure of natural products ${ }^{14}$ such as cinnamomumolide (13) ${ }^{15}$ cinncassin $\mathrm{A}_{7}$ (ent-13), ${ }^{16}$ and cinnamomulactone $(14){ }^{17}$ (Figure 2D). Therefore, we developed in this study a novel type of dirhodium(II) carboxylate catalyst and revealed that 10 , whose conformation can be controlled via chalcogen-bonding interactions, is a highly valuable catalyst for inside-type intramolecular $\mathrm{C}-\mathrm{H}$ insertion reactions.

Herein, we report the stereostructures of the sulfur-containing catalyst $\mathbf{1 0}$ and related derivatives, together with its successful application in the stereoselective inside-type $\mathrm{C}-\mathrm{H}$ insertion of $\mathbf{1 1}$ to give $\alpha, \beta$-diaryl $\gamma$-lactones 12 , as well as its extension to the total syntheses of 13 , ent 13 , and 14 (Figure 2D). 
(A) Outside-type stereoselective intramolecular $\mathrm{C}-\mathrm{H}$ insertion.

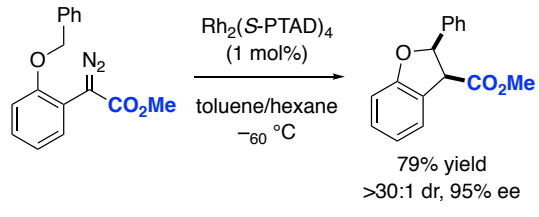

(B) Inside-type stereoselective intramolecula $\mathrm{C}-\mathrm{H}$ insertion.

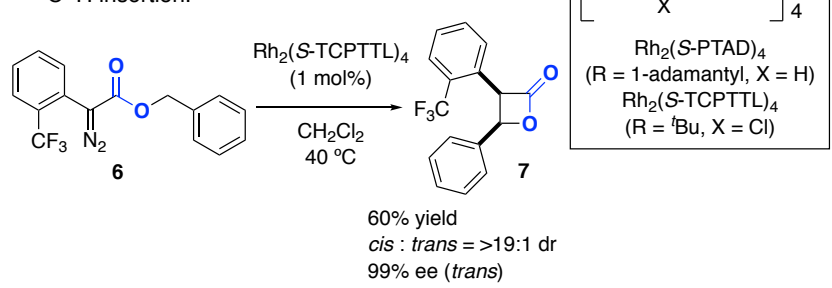

(C) Our example of inside-type $\mathrm{C}-\mathrm{H}$ insertion.

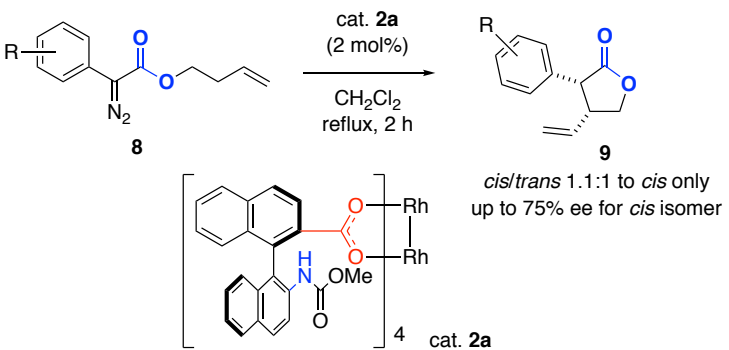

(D) This work
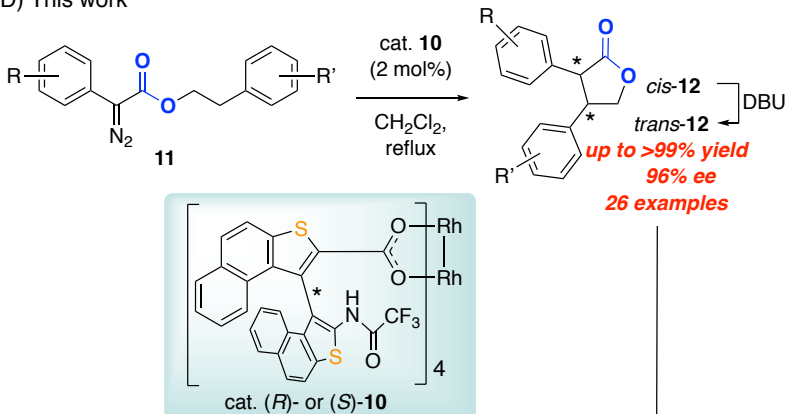
$96 \%$ ee
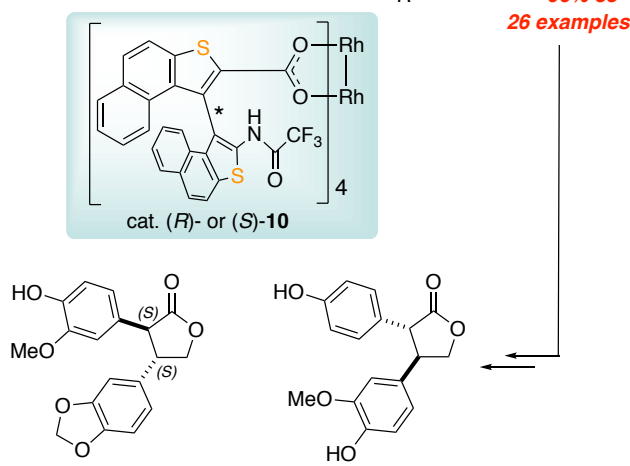

cinnamomumolide $((3 S, 4 S)$-13) cinnamomulactone (14) cinncassin $\mathrm{A}_{7}((3 R, 4 R)$-ent-13)

Figure 2. Inside- and outside-type asymmetric intramolecular $\mathrm{C}-\mathrm{H}$ insertion reactions of $\alpha$-aryl $\alpha$-diazoesters catalyzed by dirhodium(II) carboxylate complexes.

\section{RESULTS AND DISCUSSION}

\section{Preparation and Stereostructure of Dirhodium(II) Carboxylate Complexes}

Complex $(S)$-10, which bears a trifluoroacetamide group on its binaphthothiophene framework, was prepared from benzyl ester $(S)-15^{6}$ by installing a trifluoroacetamide moiety at the aniline-type amino group and successive deprotection of the benzyl group (Scheme 1). Treatment of carboxylic acid $(S)-16$ with $\mathrm{Rh}_{2}(\mathrm{OAc})_{4}$ in refluxing chlorobenzene led to a smooth ligand exchange from AcOH to $(S)-16$ on the rhodium(II) centers to afford $(S)-10$. We also prepared enantiomer $(R)-\mathbf{1 0}$, and the binaphthyl-type $\mathbf{2 b}$, which contains trifluoroacetamide groups, to compare their catalytic potential to that of 10 .

Scheme 1. Preparation of Biaryl-type Dirhodium(II) Carboxylate Complexes $2 \mathrm{~b}$ and $(S)-10$.

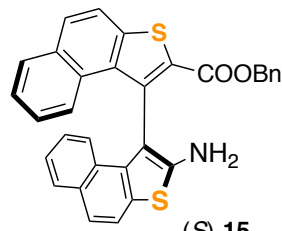

(S) -15

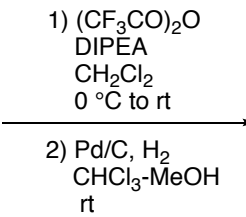

$\mathrm{rt}$

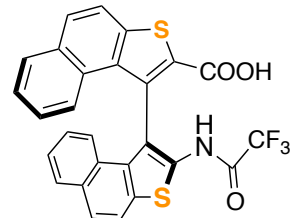

$(S)-16$

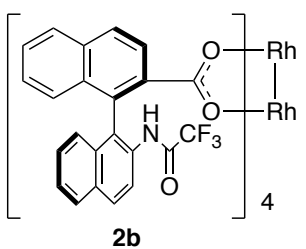

2b

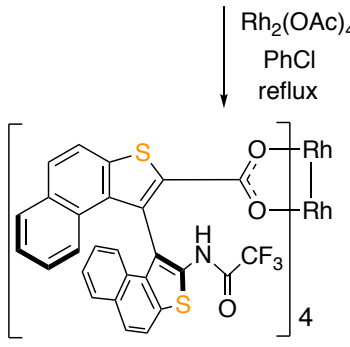

$(S)-10$
The success of the catalyst-design concept presented in Figure $1 \mathrm{D}$ was confirmed by single-crystal X-ray diffraction analyses of $(S)$ $\mathbf{1 0}$ and $\mathbf{2 b}$. The crystal structure of $\mathbf{2 b}$ is shown in Figure 3A. In the crystalline solid state, $\mathbf{2 b}$ adopts a $D_{2}$-symmetric conformation in which the amide-substituted naphthyl groups reside in an "updown-up-down" configuration. ${ }^{18,19}$ However, the structure of $\mathbf{2} \mathbf{b}$ was found to be pseudo-symmetric, i.e., the chiral environments around the two rhodium centers ( $\mathrm{Rh} 1$ and $\mathrm{Rh} 2$ ) are not identical, as indicated by the different geometries of the blue naphthyl groups located at the "up" sides relative to the Rh1 and Rh2 centers (cf. top views from Rh1 and Rh2 in Figure 3A). These inequivalent chiral environments should lead to transition states with different geometry on both $\mathrm{Rh}$ centers in the stereo-determining C-C-bond-forming step to give a mixture of products with different enantioselectivity. Indeed, $\mathbf{2} \mathbf{b}$ provided only moderate levels of enantioselectivity $(67 \%$ ee) in the intramolecular $\mathrm{C}-\mathrm{H}$ insertion of 11a to give trans-lactone 12a (Table 1 , entry 10 ). Another noteworthy property of $\mathbf{2 b}$ is the hydrogen bond formed between the carboxylate oxygen atom and the amide $\mathrm{NH}$ group (O... N distance: $2.71(1) \AA ̊$ ) in ligand II, which is shown by the dotted line in Figure 3A.

We have previously reported the solid-state stereostructure of the methoxycarbonyl-functionalized binaphthyl-type catalyst 2a (Figure 3B). ${ }^{4}$ This complex forms a $C_{2}$-symmetric conformation in which the carbamate-substituted naphthyl rings of the ligands are oriented in an "up-up-down-down" conformation. However, this complex also contains unsymmetric chiral environments around $\mathrm{Rh} 1$ and Rh2, as shown by the different geometries of the blue naphthyl groups around the Rh1 and Rh2 centers. In this complex, two hydrogen bonds were found between the carboxylate oxygen atoms and the carbamate $\mathrm{NH}$ groups of the carboxylate ligands I and II located at the upper side of the complex relative to Rh1 $(\mathrm{O} \bullet . \mathrm{N}$ distances: 2.974 (7) Å (ligand I); 2.962(7) Å (ligand II); dotted lines in Figure 3B). 

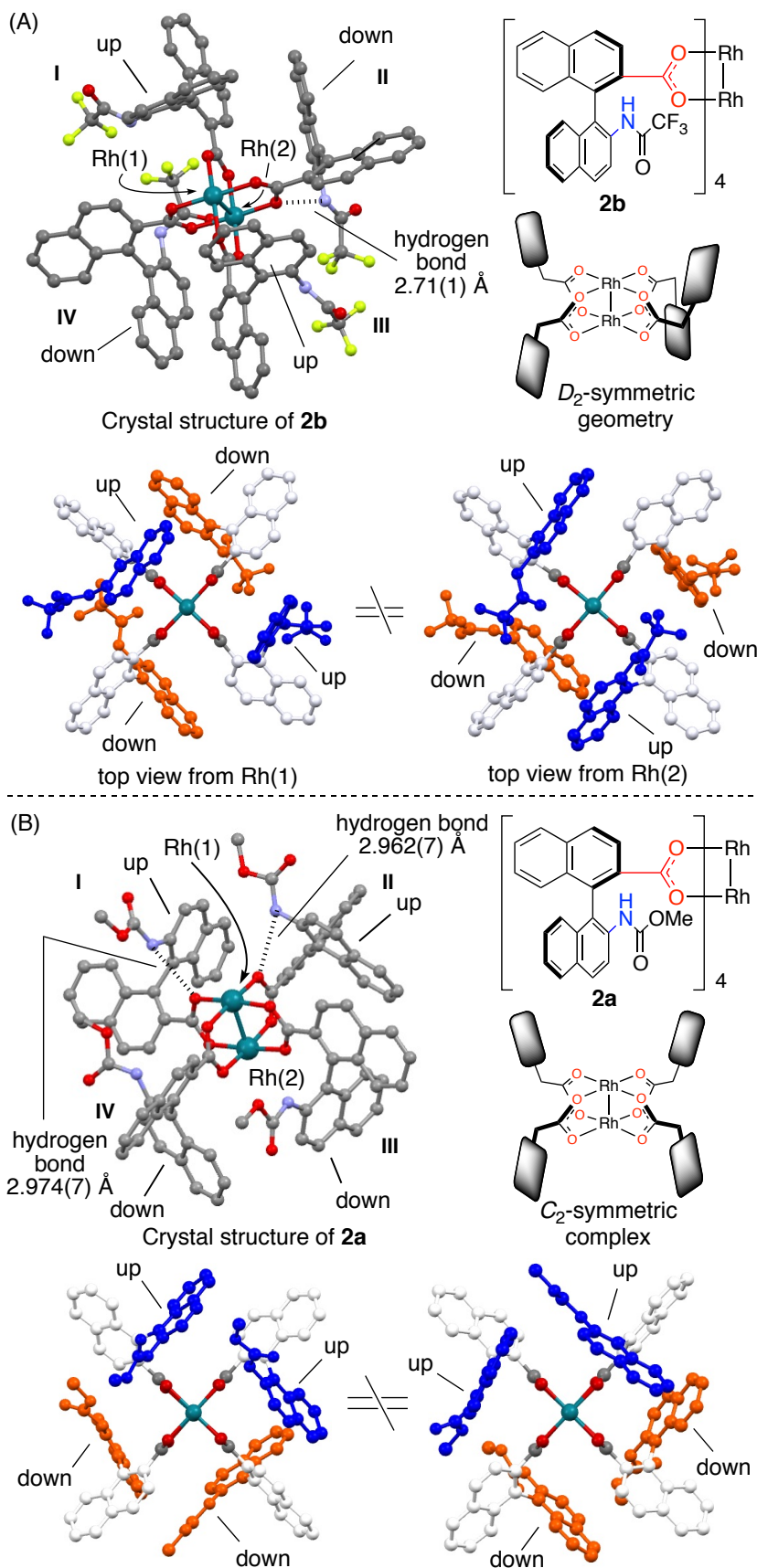

top view from $\mathrm{Rh}(1)$

(C)
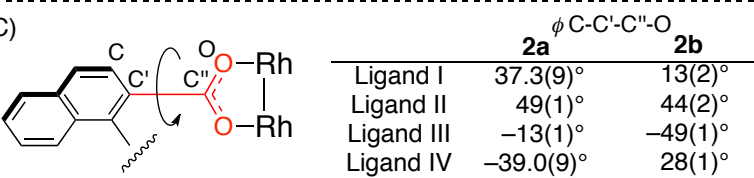

Figure 3. (A) Pseudo $D_{2}$-symmetric structure of $\mathbf{2 b}$. (B) Pseudo $C_{2}$ symmetric structure of $2 \mathrm{a}$. (C) Twist of the naphthyl rings relative to the $\pi$-face of the carboxylate group in $\mathbf{2 a}$ and $\mathbf{2} \mathbf{b}$ expressed as the dihedral angles around the carboxylate $\mathrm{C}-\mathrm{C}$ bonds of ligands I-IV. In the crystal structures of $\mathbf{2 a}$ and $\mathbf{2 b}$, the hydrogen atoms and solvent molecules coordinated at the axial positions are omitted for clarity. In the top views of the complexes, the pairs of amide-substituted naphthyl rings located at the upper and lower side relative to the indicated Rh center, are shown in blue and orange, respectively.
This complex also furnished trans-12a with unsatisfactory levels of enantioselectivity (55\% ee) (Table 1, entry 9). This was attributed to the unsymmetric chiral environments around the rhodium centers, similarly to the case of $\mathbf{2} \mathbf{b}$. The crystal structures suggested that the unsymmetric stereostructures of $\mathbf{2} \mathbf{a}$ and $\mathbf{2} \mathbf{b}$ originate from the irregular angle of the naphthyl rings relative to the $\pi$-face of the carboxylate group via the rotation of the carboxylate $\mathrm{C}-\mathrm{C}$ single bonds, as shown by the variation in their dihedral angles, i.e., $\phi \mathrm{C}-\mathrm{C}^{\prime}$ $\left.\mathrm{C}^{\prime \prime}-\mathrm{O}\right):-13(1)^{\circ}$ to $49(1)^{\circ}$ for ligands I-IV of complex $2 \mathrm{a}$, and $13(2)^{\circ}$ to -49 (1) for those of complex $\mathbf{2 b}$ (Figure 3C).

On the other hand, in sharp contrast to $\mathbf{2} \mathbf{a}$ and $\mathbf{2} \mathbf{b}$, complex $(S)$ 10 exhibits a well-ordered $D_{2}$-symmetric stereostructure in which the chiral environments around the $\mathrm{Rh} 1$ and $\mathrm{Rh} 2$ centers are almost identical (cf. the blue naphthothiophene rings in Figure 4A). ${ }^{20,21,22}$ Unlike in $\mathbf{2} \mathbf{a}$ and $\mathbf{2} \mathbf{b}$, hydrogen bonding was not observed between the carboxylate oxygen atoms and the amide $\mathrm{NH}$ groups of the ligands. Instead, as expected, four chalcogen bonds, one between the sulfur atom of the naphthothiophene ring and the oxygen atom of the carboxylate group of each ligand, were observed in ligands I-IV, and are shown as dotted lines in Figure 4A and exemplified by ligand III in Figure 4B. It should be noted here that all S...O distances (2.84(1)-2.95(1) $\AA$ ) are shorter than the sum of the van der Waals radii (3.32 Å) of these atoms (Figure 4B). These chalcogen-bonding interactions could restrict the flexibility around the carboxylate $\mathrm{C}-$ $\mathrm{C}$ bonds, thus resulting in a co-planar alignment of the carboxylate groups and the naphthothiophene $\pi$-systems in all the ligands ( $\phi \mathrm{S}$ $\left.\mathrm{C}-\mathrm{C}-\mathrm{O} \leq \pm 16(2)^{\circ}\right)$ (Figure 4B). The defined conformations of the carboxylate moieties are crucial for the nearly perfect symmetric structure of $\mathbf{1 0}$. Moreover, as expected, the co-planar geometry of the carboxylate and the naphthothiophene $\pi$-systems force the alternating naphthothiophene rings (blue) to tilt towards the Rh centers (cf. side view of the complex in Figure 4C). Due to the tilted aromatic rings in this $D_{2}$-symmetric arrangement, trapezoidal chiral spaces are formed near each $\mathrm{Rh}$ center (the chiral space around $\mathrm{Rh} 2$ is indicated by a dotted line).

Furthermore, chalcogen bonds between the carbonyl oxygen atom of the trifluoroacetamide moiety and a sulfur atom are also observed in all these ligands ( $\mathrm{S}^{\prime}$... O' distances: $2.82(2)-2.97(2) \AA$ ) (Figure 4B). These chalcogen-bonding interactions cause the trifluoroacetamide moieties to form a five-membered 'heterocycle' parallel to the naphthothiophene rings (Figure 4B). The space-filling model of $\mathbf{1 0}$ revealed that a wide chiral cleft is formed by the fused cyclic systems of the naphthothiophene and trifluoroacetamide moieties (Figure 4D). Having successfully achieved promising symmetry and defined structural properties for asymmetric induction, we then moved to examine inside-type intramolecular $\mathrm{C}-\mathrm{H}$ insertion reactions using complex 10.

\section{Inside-type Intramolecular C-H Insertion Reactions and Total Syn- thesis of Natural Products}

The potential for asymmetric induction of each $\mathrm{Rh}$ complex was evaluated in the intramolecular $\mathrm{C}-\mathrm{H}$ insertion reaction of $11 \mathrm{a}$, as the product of this reaction provides ready access to cinnamomumolide (13) (Table 1).

After finding appropriate conditions by screening solvents and temperature (for details, see the SI), the intramolecular C-H 


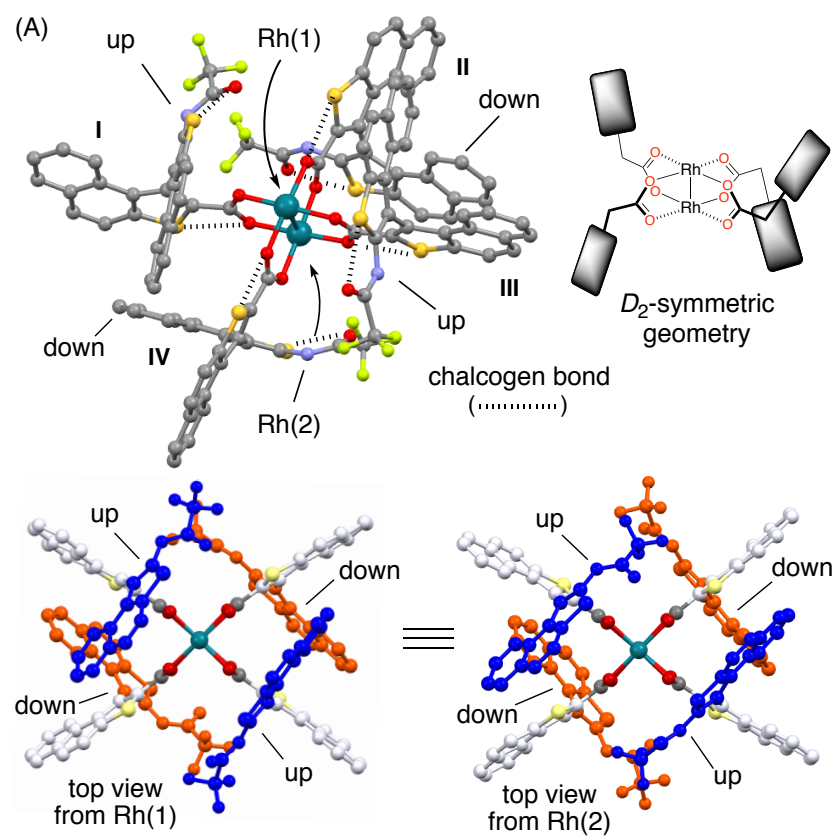

insertion was examined in the presence of $2.0 \mathrm{~mol} \%$ of the dirhodium(II) carboxylate complex in refluxing $\mathrm{CH}_{2} \mathrm{Cl}_{2}$. In all cases, cis12a was obtained as the initial product in perfect diastereoselectivity ( cis : trans $>99: 1$ ). However, although cis-12a was isolable, isomerization of cis-12a to trans-12a was sometimes observed during the isolation. Therefore, epimerization to trans-12a was carried out by treatment with DBU after work up of the $\mathrm{C}-\mathrm{H}$ insertion reaction. The chemical yield of cis-12a was determined using an internal standard, and the asymmetric induction was evaluated using the enantiomeric excess (ee) of trans-12a. The same ee value (95\% ee) was measured for the isolated cis-12a and trans-12a, demonstrating that no change in the optical purity occurred during the epimerization (entry 11 vs. 12).

Initial trials of this reaction using several established catalysts, including $\mathrm{Rh}_{2}(S \text {-DOSP })_{4},{ }^{23} \mathrm{Rh}_{2}(S \text {-PTTL })_{4},{ }^{24} \mathrm{Rh}_{2}(R \text {-TCPTTL })_{4},{ }^{25}$ $\mathrm{Rh}_{2}(S \text {-PTAD })_{4}{ }^{11 \mathrm{c}} \quad \mathrm{Rh}_{2}(S \text {-NTTL })_{4}{ }^{26} \quad \mathrm{Rh}_{2}(S \text {-BTPCP })_{4}{ }^{27}$ and $\mathrm{Rh}_{2}(5 R \text {-MEPY })_{4}{ }^{28}$ resulted in only low to medium levels of enantioselectivity (Table 1, entries 1-7). Moreover $\mathbf{2 a}, \mathbf{2 b}$, and binaphthyltype catalyst $17^{29}$ were also tested. The use of $\mathbf{1 7} \mathrm{did}$ not improve the ee (29\%; entry 8$)$. On the other hand, the pseudo $C_{2}$-symmetric catalyst 2a (Figure 3B) furnished trans-12a in 55\% ee (entry 9), while pseudo $D_{2}$-symmetric $\mathbf{2 b}$ (Figure $3 \mathrm{~A}$ ) further improved the enantioselectivity to give trans-12a in $84 \%$ yield with $67 \%$ ee (entry 10 ). Although the stereoselectivity was still unsatisfactory, some improvement was observed using binaphthyl-type catalysts $\mathbf{2 a}$ and $\mathbf{2 b}$ instead of 17 (entries 9 and 10 vs. entry 8 ). While the different symmetry of the Rh complexes should significantly affect their performance with respect to enantioselectivity, the hydrogen bond formed between the carboxylate oxygen atom and the $\mathrm{NH}$ group of the amide and the carbamate substituents in $\mathbf{2} \mathbf{a}$ and $\mathbf{2} \mathbf{b}$ might also contribute to their increased stereoselectivity by acting as a conformational lock. A plausible explanation for the limited enantioselectivity of $\mathbf{2 a}$ and $\mathbf{2 b}$ might be the inequivalent chiral environments around their rhodium centers $(\mathrm{Rh}(1)$ and $\mathrm{Rh}(2))$ (Figs. 3A and 3B). These inequivalent chiral environments might lead to a decrease in enantioselectivity through transition states with different geometry in the stereo-determining C-C-bond-forming step. Thus, we examined the binaphthothiophene catalyst 10.

As expected, the stereoselectivity was dramatically improved by the trifluoroacetamide-bearing $(R)-10$, which gave trans-12a in $95 \%$ yield with $95 \%$ ee (entry 11 ). The initial product of the $\mathrm{C}-\mathrm{H}$ insertion, cis-12a, was isolated in $95 \%$ yield with $95 \%$ ee under the same conditions (entry 12). These results confirm that 10 is valuable for preparing both the corresponding cis- and trans-isomers in high diastereo- and enantioselectivity. As described below, the absolute configuration of trans-12a was determined as $3 S, 4 S$ by comparison of its optical rotation after transformation into cinnamomumolide (13).

The remarkable improvement in enantioselectivity using 10 corroborates the importance of conformational control of the paddlewheel catalyst to give uniform and defined chiral environments around the catalytically active centers. This improvement further highlights the value of the conformational control of ligands through chalcogen-bonding interactions. Furthermore, not only the stereoselectivity, but also the chemical yield of the product improved when 10 was used. In this reaction, the dimerization of substrate 11a tends to compete with the intramolecular $\mathrm{C}-\mathrm{H}$ insertion to generate side products. ${ }^{30}$ The well-defined and rigid pockets formed by the 
Table 1. Survey of Dirhodium(II) Carboxylate Catalysts Tested in the Asymmetric Intramolecular C-H Insertion of $11 \mathrm{a} .{ }^{a}$

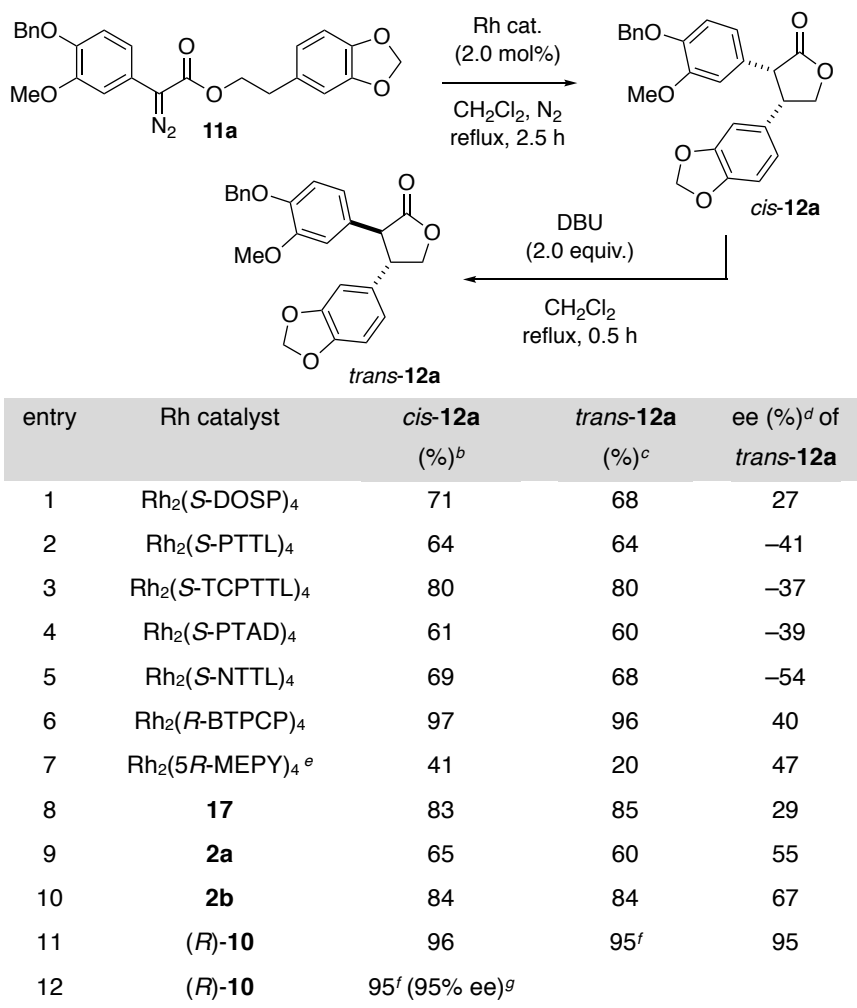

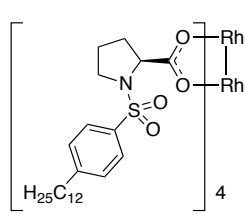

$\mathrm{Rh}_{2}(S-\mathrm{DOSP})_{4}$

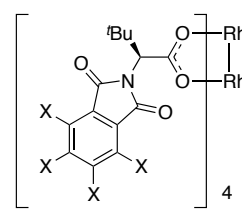

$\mathrm{R}=\mathrm{H}, \mathrm{Rh}_{2}(S-\mathrm{PTTL})_{4}$ $\mathrm{R}=\mathrm{Cl}, \mathrm{Rh}_{2}(S-\mathrm{TCPTTL})_{4}$

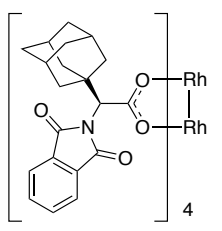

$\mathrm{Rh}_{2}(S-P T A D)_{4}$

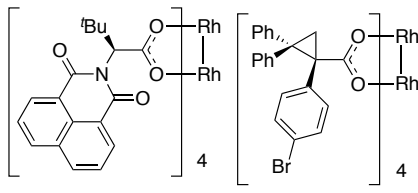

$\mathrm{Rh}_{2}(S-\mathrm{NTTL})_{4} \quad \mathrm{Rh}_{2}(R-\mathrm{BTPCP})_{4}$

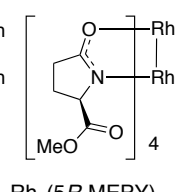

$\mathrm{Rh}_{2}(5 R-\mathrm{MEPY})_{4}$

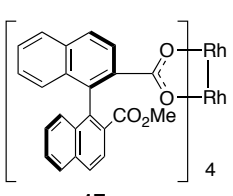

17
${ }^{a}$ Standard reaction conditions: $11 \mathrm{a}(33.5 \mathrm{mg}, 0.075 \mathrm{mmol}, 1.0$ equiv. $)$ in degassed $\mathrm{CH}_{2} \mathrm{Cl}_{2}(0.75 \mathrm{~mL})$ was added over $1.5 \mathrm{~h}$ to $4.5 \mathrm{~mL}$ of a refluxing $\mathrm{CH}_{2} \mathrm{Cl}_{2}$ solution of the dirhodium(II) catalyst ( $1.5 \mu \mathrm{mol}, 2.0 \mathrm{~mol} \%$ ); then, refluxing was continued for $1 \mathrm{~h} .{ }^{b}$ Determined by integrating the ${ }^{1} \mathrm{H}$ NMR signals in the presence of the internal standard 1,3,5-trimethoxybenzene. NMR yield over two steps. ${ }^{d}$ Determined by chiral HPLC analysis. ${ }^{e} 5 \mathrm{~mol} \%$ of $\mathrm{Rh}_{2}(5 R \text {-MEPY })_{4}$ was used. ${ }^{f}$ Isolated yield. ${ }^{8} \mathrm{Ee}(\%)$ of isolated cis-12a.

naphthothiophene rings around the $\mathrm{Rh}$ centers of $\mathbf{1 0}$ might also help to prevent these side reactions.

Having achieved satisfactory results using 10 , we then explored its substrate scope. First, we tested substrates with a variety of $\alpha$-aryl groups (Table $2 \mathrm{~A}$ ). The reactions of unsubstituted $\mathbf{1 1 b}$ and of $11 \mathrm{c}-$ 11e, which contain halogen groups at the para- or meta-positions, gave the corresponding products (cis- and trans-12b-12e) in good yield with excellent enantioselectivity (90-95\% ee). The presence of a $t$-Bu group at the para-position of $\mathbf{1 1 f}$ was still acceptable. On the other hand, a remarkable decrease in the chemical yield was observed in the reactions of para-methoxy-substituted $\mathbf{1 1}$, with $34 \%$ yield of the trans-isomer, although the enantioselectivity remained high. This could be due to the decreased electrophilicity of the rhodium-carbenoid intermediate formed by the $\alpha$-phenyl moiety with an electron-donating para-methoxy group. In contrast, $11 \mathrm{~h}$, which contains two methoxy groups at its meta-positions, afforded cis-12h in high yield and 93\% ee. The electron-withdrawing inductive effect of the meta-substituted methoxy groups may have contributed to this high yield. Naphthyl groups were also accepted and furnished cis- and trans-12i and $12 \mathbf{j}$ in excellent yield, whereby $\mathbf{1 2} \mathbf{j}$ showed the highest enantioselectivity of all products ( $96 \%$ ee). The absolute configuration of trans-12b $(3 S, 4 S)$ was determined by comparison of its optical rotation to literature values ${ }^{31}$ (cf. SI), and the absolute configuration of the other products was assigned in analogy.

Subsequently, we tested the effect of the ester moiety (Table $2 \mathrm{~B})$. The reactions of the tested substrates generally proceeded with high enantioselectivity (87\%-93\% ee for trans-12k-12r), although their chemical yield varies depending on the electronic nature of the aromatic rings. While the methoxy-functionalized substrates 110 and $11 \mathrm{p}$ afforded the products in excellent yield, substrates $11 \mathrm{k}-11 \mathrm{n}$, which bear electron-withdrawing groups, furnished the corresponding $\gamma$-lactones in moderate yield. This may have been due to the poorer stabilization of the positive charge at the benzylic position generated in the transition state for $\mathrm{C}-\mathrm{H}$ insertion. Unfortunately, the $\mathrm{C}-\mathrm{H}$ insertion of thiophene derivative 11 s and our previous substrate 8 did not produce promising results, providing the corresponding products trans-12s and trans -9 in $46 \%$ yield and $77 \%$ ee as well as $26 \%$ yield and $75 \%$ ee, respectively.

Substrates bearing bromo, alkoxy, or 2-naphthyl groups on the $\alpha$-aryl groups and electron-abundant aromatic groups in ester moieties generally furnished the corresponding products in high yield and enantioselectivity (Table 2C). It is noteworthy that substrate 11 was reasonably converted on the gram scale at a reduced catalyst loading $(0.5 \mathrm{~mol} \%)$ to give trans-12t in $90 \%$ yield and $93 \%$ ee (cf. dashed box). In the case of $12 \mathrm{u}$ and $\mathbf{1 2 v}$, the cis- $\gamma$-lactones were isolated to demonstrate the utility of this reaction for producing the cisisomer.

Having established the substrate scope, we then applied the reaction to the total syntheses of naturally occurring $\gamma$-lactones. Cinnamomumolide (13), which exhibits a $3 S, 4 S$ configuration, and its enantiomer, cinncassin $A_{7}$ (ent-13), which exhibits a $3 R, 4 R$-configuration, were readily prepared by removal of the benzyl group of the enantiomers trans-12a and ent-trans-12a (Scheme 2). Substrate 11a was prepared from the commercially available compounds 18 and 19 in two steps. Therefore, cat. 10 enables the five-step stereoselective total syntheses of 13 and ent-13 in 59\% and 51\% total yield, respectively. The absolute configurations of the prepared compounds were confirmed by comparison of their optical rotation with literature values. ${ }^{15 b, 16}$ Furthermore, the total synthesis of cinnamomulactone (14) was achieved in five steps via the asymmetric intramolecular $\mathrm{C}-\mathrm{H}$ insertion of $11 z$, which was prepared from commercially available 20 and 21 , in the presence of $(S)$-10, followed by deprotection of the benzyl groups of $12 z$ (Scheme 3). Compound 14 was synthesized in the naturally occurring form, given that the optical rotation of 
Table 2. Intramolecular C-H Insertion to Give a Variety of Cis- and Trans- $\gamma$-lactones. ${ }^{2}$

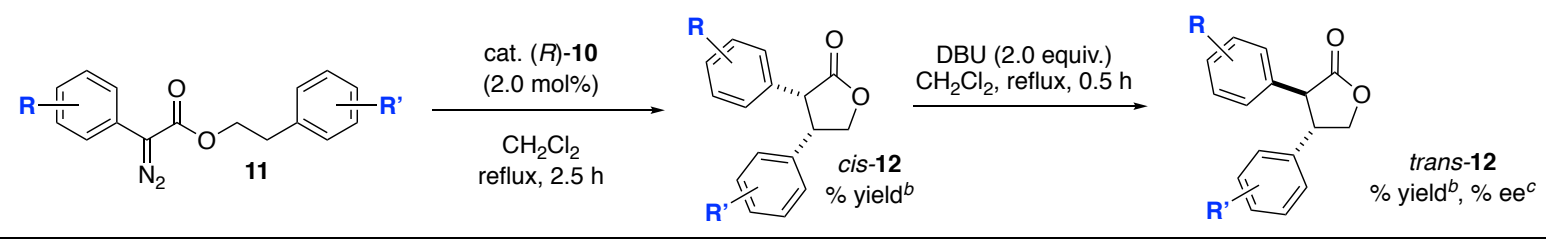

(A)
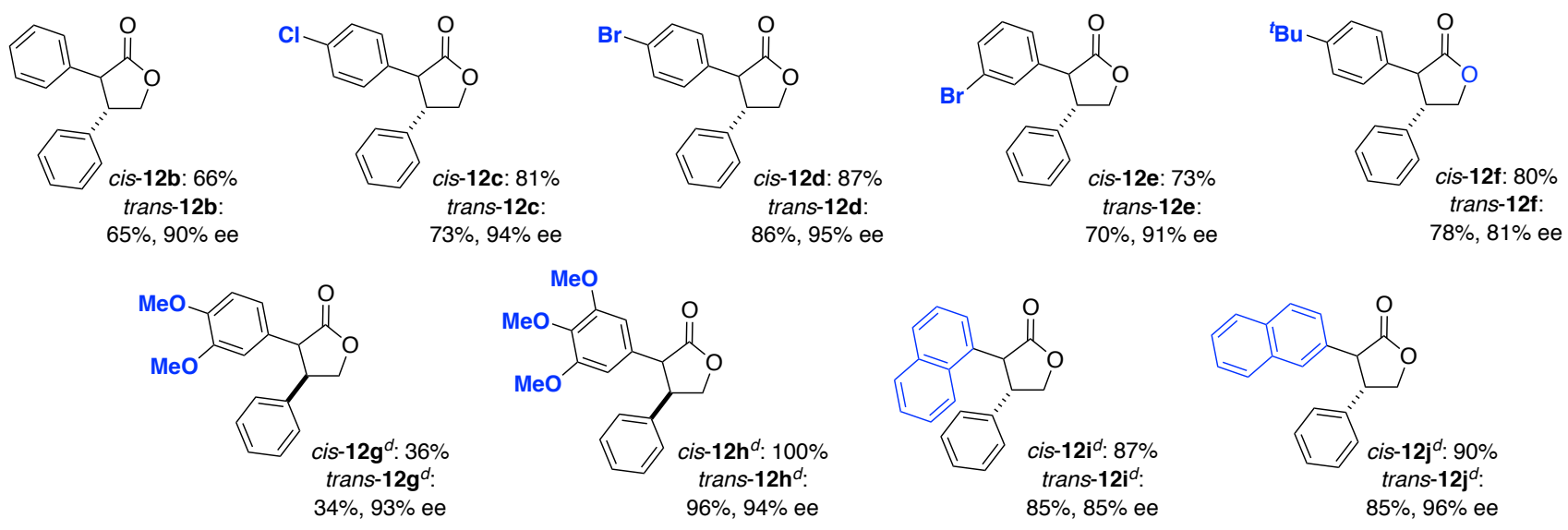

(B)
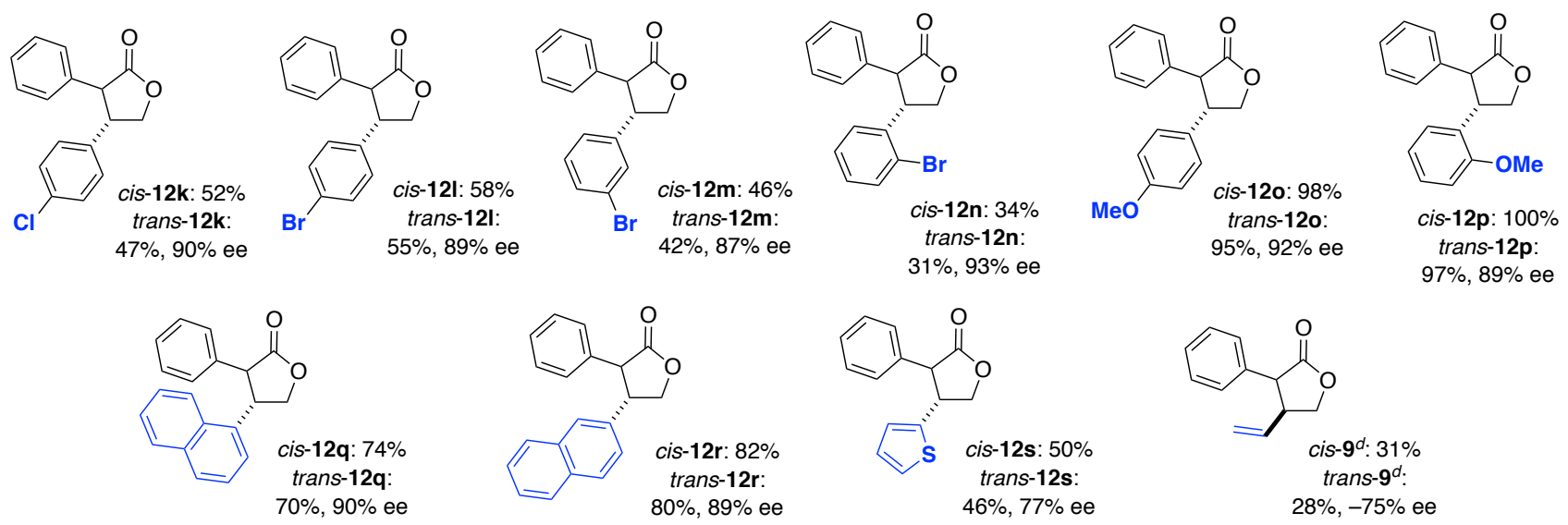

(C)
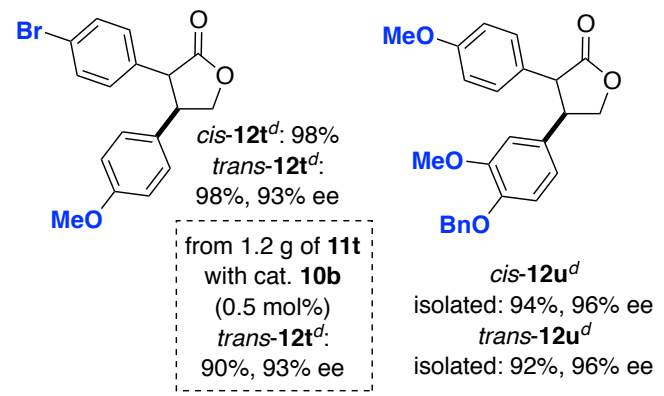

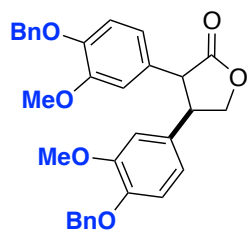

cis-12v $\mathbf{v}^{d}$

isolated: $85 \%, 95 \%$ ee trans-12v $\mathbf{v}^{d}$

isolated: $88 \%$, $95 \%$ ee

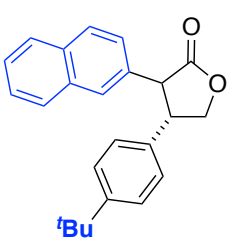

cis-12w: $99 \%$ trans-10w:

$97 \%, 92 \%$ ee

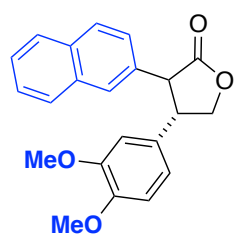

cis-12x: $98 \%$ trans-12x:

$97 \%, 95 \%$ ee

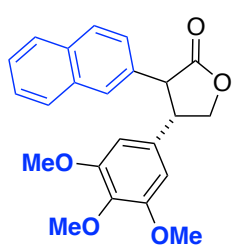

cis-12y: $100 \%$ trans-12y: $99 \%, 94 \%$ ee

${ }^{a}$ Standard reaction conditions: $11(0.075 \mathrm{mmol}, 1.0$ equiv. $)$ in degassed $\mathrm{CH}_{2} \mathrm{Cl}_{2}(0.75 \mathrm{~mL})$ was added over $1.5 \mathrm{~h}$ to $4.5 \mathrm{~mL}$ of a refluxing $\mathrm{CH}_{2} \mathrm{Cl}_{2}$ solution of 10 (3.43 mg, $1.5 \mu \mathrm{mol}, 2.0 \mathrm{~mol} \%)$; then, refluxing was continued for $1 \mathrm{~h} .{ }^{b}$ Determined by integrating the ${ }^{1} \mathrm{H}$ NMR signals in the presence of the internal standard 1,3,5-trimethoxybenzene, except in the cases of $12 \mathbf{u}$ and $12 v$. ${ }^{C}$ Determined by chiral HPLC analysis. ${ }^{d}$ Catalyst $(S)$-10 was used.

synthesized 14 had the same sign as the isolated one from natural source. ${ }^{17}$ However, the absolute configuration of 14 has not yet been determined, although the $3 R, 4 R$ configuration was elucidated based on the opposite sign of the optical rotation $\left([\alpha]_{\mathrm{D}}^{25}=-193\right.$ in $\left.\mathrm{CH}_{2} \mathrm{Cl}_{2}\right)$ relative to that of cinnamomumolide $(13)\left([\alpha]_{\mathrm{D}}{ }^{25}=+161.5\right.$ in $\left.\mathrm{CH}_{2} \mathrm{Cl}_{2}\right) .{ }^{17}$ To determine the absolute configuration of $\mathbf{1 4}$ unambiguously, the $\mathrm{CD}$ spectra of synthesized cinnamomumolide $(3 S, 4 S)-13$, cinnacassin $\mathrm{A}_{7}(3 R, 4 R)$-ent-13, and 14 were compared (Figure 5). Both 14 and ent-13 show negative Cotton effects at 
Scheme 2. Asymmetric Syntheses of Cinnamommumolide (13) and Its Enantiomer Cinnacassin A7 (ent-13).<smiles>COc1cc(CC(=O)O)ccc1OCc1ccccc1</smiles>
18 19

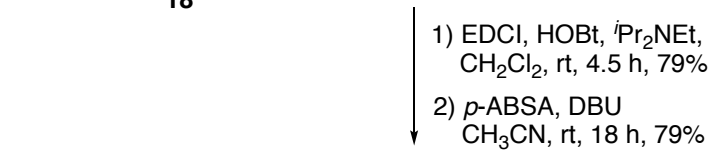

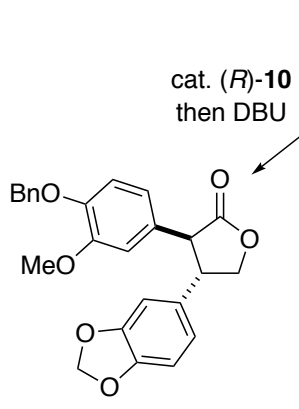

trans-(3S,4S)-12a

$95 \%$ yield, $95 \%$ ee

$$
\mid \begin{aligned}
& \mathrm{H}_{2}, \mathrm{Pd} / \mathrm{C} \\
& \mathrm{CHCl}_{3} / \mathrm{EtOH} \\
& \text { rt., quant. }
\end{aligned}
$$<smiles>COc1cc(C2C(=O)OC[C@H]2c2ccc3c(c2)OCO3)ccc1O</smiles>

cinnamomumolide (13)

$59 \%$ yield over 5 steps $95 \%$ ee

$[\alpha]_{D}^{20}=+201.7$

(c $0.4, \mathrm{CH}_{2} \mathrm{Cl}_{2}$ )

Lit. for cinnamomumolide $(3 S, 4 S)^{15 b}$

$[\alpha]_{D}^{25}=+161.5\left(c 0.4, \mathrm{CH}_{2} \mathrm{Cl}_{2}\right)$

Scheme 3. Asymmetric Synthesis of Cinnamomulactone (14).

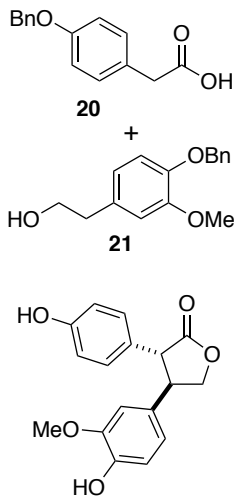

cinnamomulactone (14)

$30 \%$ yield over 5 steps $96 \%$ ee

(c $0.2, \mathrm{MeOH})$
$[\alpha]_{D}^{20}=-257.8$
1) $\mathrm{EDCl}, \mathrm{HOBt}$

${ }^{i} \mathrm{Pr}_{2} \mathrm{NEt}, \mathrm{CH}_{2} \mathrm{Cl}_{2} \mathrm{BnO}$ rt., $14 \mathrm{~h}, 59 \%$

2) $p$-ABSA

DBU, MeCN

$0^{\circ} \mathrm{C}$ to rt., $24 \mathrm{~h}$
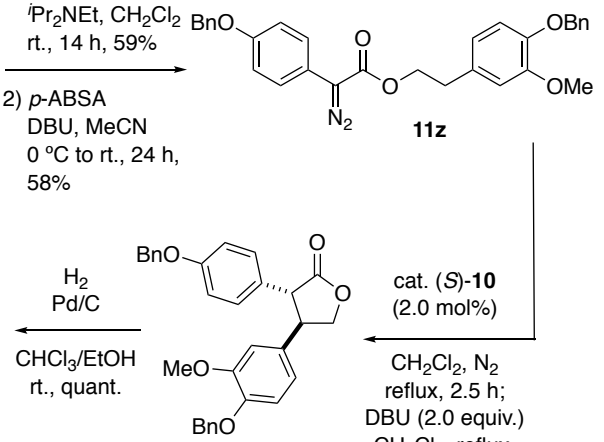

trans-12z $88 \%$ yield, $96 \%$ ee cat. (S)-10

then DBU

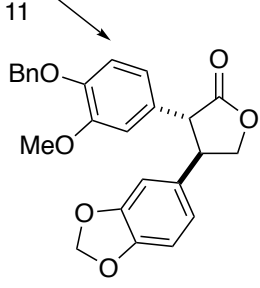

trans-(3R,4R)-12a

$81 \%$ yield, $96 \%$ ee

$$
\mid \begin{aligned}
& \mathrm{H}_{2}, \mathrm{Pd} / \mathrm{C} \\
& \mathrm{CHCl}_{3} / \mathrm{EtOH} \\
& \text { rt., quant. }
\end{aligned}
$$

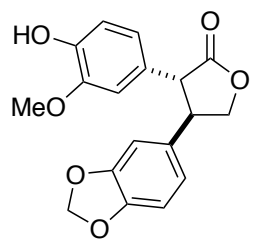

cinncassin $\mathrm{A}_{7}$ (ent-13) $51 \%$ yield over 5 steps $96 \%$ ee

$[\alpha]_{D}{ }^{16}=-213.4$

(c $0.3, \mathrm{MeOH})$

Lit. for cinncassin $\mathrm{A}_{7}(3 R, 4 R)^{16}$ $[\alpha]_{D}^{25}=-193(c 0.4, \mathrm{MeOH})$

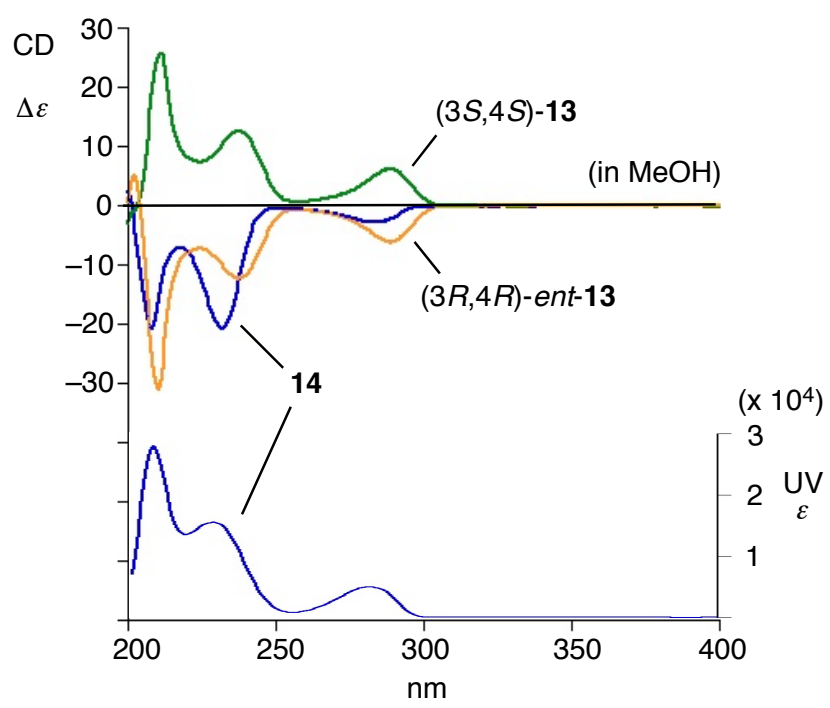

Figure 5. CD and UV spectra of 13, ent-13, and 14 in $\mathrm{MeOH}$.

$270-300 \mathrm{~nm}, 230-250 \mathrm{~nm}$, and $200-220 \mathrm{~nm}$, which clearly indicates a $3 R, 4 R$-configuration of 14 . The mirror image pattern of the $\mathrm{CD}$ spectra for 14 and $(3 S, 4 S)-13$ also support the $3 R, 4 R$-configuration of 14 . These asymmetric total syntheses aptly demonstrate the high applicability of $\mathbf{1 0}$ for the preparation of optically active $\alpha, \beta$-diaryl $\gamma$ lactones.

\section{CONCLUSIONS}

Chiral dirhodium(II) carboxylate complex 10, which is conformationally controlled via chalcogen-bonding interactions, was developed. A single-crystal X-ray diffraction analysis indicated that the $\mathrm{Rh}$ centers in $\mathbf{1 0}$ are embedded in uniform and defined chiral environments that arise from the presence of intramolecular chalcogen bonds. 10 demonstrated outstanding catalytic performance in diastereo- and enantioselective inside-type intramolecular $\mathrm{C}-\mathrm{H}$ insertion reactions, as well as versatile synthetic utility in the concise asymmetric syntheses of the naturally occurring $\alpha, \beta$-disubstituted $\gamma$ lactones such as 13, ent-13, and 14. These results demonstrate the importance of establishing conformational control in chiral paddlewheel complexes in order to achieve remarkable asymmetric induction. Furthermore, these results highlight the effectiveness of a noncovalent interaction in controlling the conformation of catalysts that bear a rotatable bond near the catalytically active center. Further examination and applications of this concept of establishing conformational control via chalcogen bonding in asymmetric catalysts are currently in progress in our laboratories.

\section{ASSOCIATED CONTENT}

\section{Supporting Information}

The Supporting Information is available free of charge on the ACS Publications website.

Experimental procedures and spectroscopic data for all new compounds (PDF). 


\section{AUTHOR INFORMATION}

\section{Corresponding Author}

- Takumi Furuta - Department of Pharmaceutical Chemistry, Kyoto Pharmaceutical University, Yamashina-ku, Kyoto 607-8414, Japan; E-mail: furuta@mb.kyoto-phu.ac.jp

\section{Author Contributions}

The manuscript was collated by contributions from all authors.

\section{ACKNOWLEDGMENTS}

This work was financially supported by a Grant-in-Aid for Scientific Research (C) (25460007) and Scientific Research (B) (18H02554).

\section{REFERENCES}

(1) (a) Davies, H. M. L.; Beckwith, R. E. J. Catalytic Enantioselective C-H Activation by Means of Metal-Carbenoid-Induced C-H Insertion. Chem. Rev. 2003, 103, 2861-2903. (b) Slattery, C. N.; Ford, A.; Maguire, A. R. Catalytic Asymmetric $\mathrm{C}-\mathrm{H}$ Insertion Reactions of $\alpha$-Diazocarbonyl Compounds. Tetrahedron 2010, 66, 6681-6705. (c) Doyle, M. P.; Duffy, R.; Ratnikov, M.; Zhou, L. Catalytic Carbene Insertion into C-H Bonds. Chem. Rev. 2010, 110, 704-724. (d) Doyle, M. P.; Liu, Y.; Ratnikov, M. Catalytic, Asymmetric, Intramolecular Carbon-Hydrogen Insertion. Org. React. 2013, 80, 1-131. (e) Ford, A.; Miel, H.; Ring, A.; Slattery, C. N.; Maguire, A. R.; McKervey, M. A. Modern Organic Synthesis with $\alpha$-Diazocarbonyl Compounds. Chem. Rev. 2015, 115, 9981-10081.

(2) Hansen, J.; Davies, H. M. L. High Symmetry Dirhodium(II) Paddlewheel Complexes as Chiral Catalysts. Coord. Chem. Rev. 2008, 252, 545555.

(3) Furuta, T.; Yamamoto, J.; Kitamura, Y.; Hashimoto, A.; Masu, H.; Azumaya, I.; Kan, T; Kawabata, T. Synthesis of Axially Chiral Amino Acid and Amino Alcohols via Additive-Ligand-Free Pd-Catalyzed Domino Coupling Reaction and Subsequent Transformations of the Product Amidoaza[5] helicene. J. Org. Chem. 2010, 75, 7010-7013.

(4) Lu, W.-j.; Xu, P.; Murai, T.; Sasamori, T.; Tokitoh, N.; Kawabata, T.; Furuta, T. Asymmetric Intramolecular C-H Insertion Promoted by Dirhodium(II) Carboxylate Catalyst Bearing Axially Chiral Amino Acid Derivatives. Synlett 2017, 28, 679-683.

(5) Murai, T.; Xing, Y.; Kuribayashi, T.; Lu, W.; Guo, J.-D.; Yella, R.; Hamada, S.; Sasamori, T.; Tokitoh, N.; Kawabata, T.; Furuta, T. Synthesis and Structural Properties of Axially Chiral Binaphthothiophene Dicarboxylic Acid. Chem. Pharm. Bull. 2018, 66, 1203-1206.

(6) Hamada, S.; Wang, S.; Murai, T.; Xing, Y.; Inoue, T.; Ueda, Y.; Sasamori, T.; Kawabata, T.; Furuta, T. Synthesis of Axially Chiral Binaphthothiophene $\delta$-Amino Acid Derivatives Bearing Chalcogen Bonds. Heterocycles 2020, $101,328-338$

(7) (a) Nagao, Y.; Hirata, T.; Goto, S.; Sano, S.; Kakehi, A.; Iizuka, K.; Shiro, M. Intramolecular Nonbonded S...O Interaction Recognized in (Acylimino)thiadiazoline Derivatives as Angiotensin II Receptor Antagonists and Related Compounds. J. Am. Chem. Soc. 1998, 120,3104-3110. (b) Iwaoka, M.; Takemoto, S.; Tomoda, S. Statistical and Theoretical Investigations on the Directionality of Nonbonded S...O Interactions. Implications for Molecular Design and Protein Engineering. J. Am. Chem. Soc. 2002, 124, 10613-10620. (c) Beno, B. R.; Yeung, K.-S.; Bartberger, M. D.; Pennington, L. D.; Meanwell, N. A. A Survey of the Role of Noncovalent Sulfur Interactions in Drug Design. J. Med. Chem. 2015, 58, 4383-4438. (d) Pascoe, D. J.; Ling, K. B.; Cockroft, S. L. The Origin of Chalcogen-Bonding Interactions. J. Am. Chem. Soc. 2017, 139, 15160-15167. (e) Huang, H.; Yang, L.; Facchetti, A.; Marks, T. J. Organic and Polymeric Semiconductors Enhanced by Noncovalent Conformational Locks. Chem. Rev. 2017, 117, 10291-10318. (8) (a) Benz, S.; López-Andarias, J.; Mareda, J. Sakai, N.; Matile, S. Catalysis with Chalcogen Bonds. Angew. Chem., Int. Ed. 2017, 56, 812-815. (b) Benz, S.; Mareda, J.; Besnard, C.; Sakai, N.; Matile, S. Catalysis with Chalcogen Bonds: Neutral Benzodiselenazole Scaffolds with High-Precision Selenium
Donors of Variable Strength. Chem. Sci. 2017, 8, 8164-8169. (c) Wang, W.; Zhu, H.; Liu, S.; Zhao, Z.; Zhang, L.; Hao, J.; Wang, Y. Chalcogen-Chalcogen Bonding Catalysis Enables Assembly of Discrete Molecules. J. Am. Chem. Soc. 2019, 141, 9175-9179. (d) Young, C. M.; Elmi, A.; Pascoe, D. J.; Morris, R. K.; McLaughlin, C.; Woods, A. M.; Frost, A. B.; de la Houpliere, A.; Ling, K. B.; Smith, T. K.; Slawin, A. M. Z.; Willoughby, P. H.; Cockroft, S. L.; Smith, A. D. The Importance of 1,5-Oxygen …Chalcogen Interactions in Enantioselective Isochalcogenourea Catalysis. Angew. Chem., Int. Ed. 2020, 59, 3705-3710. (e) Wang, W.; Zhu, H.; Feng, L.; Yu, Q.; Hao, J.; Zhu, R.; Wang, Y. Dual Chalcogen-Chalcogen Bonding Catalysis. J. Am. Chem. Soc. 2020, 142, 3117-3124

(9) (a) Riwer, L.; Trapp, N.; Root, K.; Zenobi, R.; Diederich, F. Supramolecular Capsules: Strong Versus Weak Chalcogen Bonding. Angew. Chem. Int. Ed. 2018, 57, 17259-17264. (b) Rahman, F.-J.; Tzeli, D.; Petsalakis, I. D.; Theodorakopoulos, G.; Ballester, P.; Rebek, J. Jr.; Yu, Y. Chalcogen Bonding and Hydrophobic Effects Force Molecules into Small Spaces. J. Am. Chem. Soc. 2020, 142, 5876-5883.

(10) Halogen binding interactions were found in the dirhodium carboxylate complexes $\mathrm{Rh}_{2}(\mathrm{~S} \text {-TCPTTL })_{4}$ and its bromo derivative. These interactions are considered to work as a conformational lock for their $C_{4}$-symmetric structures. For details, see: (a) Goto, T.; Takeda, K.; Shimada, N.; Nambu, H.; Anada, M.; Shiro, M.; Ando, K.; Hashimoto, S. Highly Enantioselective Cyclopropanation Reaction of 1-Alkynes with $\alpha$-Alkyl- $\alpha$-Diazoesters Catalyzed by Dirhodium(II) Carboxylates. Angew. Chem., Int. Ed. 2011, 50, 6803-6808. (b) Lindsay, V. N. G.; Lin, W.; Charette, A. B. Experimental Evidence for the All-Up Reactive Conformation of Chiral Rhodium(II) Carboxylate Catalysts: Enantioselective Synthesis of cis-Cyclopropane $\alpha$ Amino Acid. J. Am. Chem. Soc. 2009, 131, 16383-16385.

(11) For examples of stereoselective outside-type intramolecular $\mathrm{C}-\mathrm{H}$ insertions for the syntheses of $\alpha, \beta$-disubstituted dihydrobenzofurans, see: (a) Davies, H. M. L.; Grazini, M. V. A.; Aouad, E. Asymmetric Intramolecular C-H Insertions of Aryldiazoacetates. Org. Lett. 2001, 3, 1475-1477. (b) Saito, H.; Oishi, H.; Kitagaki, S.; Nakamura, S.; Anada, M.; Hashimoto, S. Enantio- and Diastereoselective Synthesis of cis-2-Aryl-3-methoxycarbonyl-2,3-dihydrobenzofurans via the $\mathrm{Rh}(\mathrm{II})$-Catalyzed $\mathrm{C}-\mathrm{H}$ Insertion Process. Org. Lett. 2002, 4, 3887-3890. (c) Reddy, R. P.; Lee, G. H.; Davies, H. M. L. Dirhodium Tetracarboxylate Derived from Adamantylglycine as a Chiral Catalyst for Carbenoid Reactions. Org. Lett. 2006, 8, 3437-3440. (d) Koizumi, Y.; Kobayashi, H.; Wakimoto, T.; Furuta, T.; Fukuyama, T.; Kan, T. Total Synthesis of (-)-Serotobenine. J. Am. Chem. Soc. 2008, 130, 16854-16855. (e) Natori, Y.; Tsutsui, H.; Sato, N.; Nakamura, S.; Nambu, H.; Shiro, M.; Hashimoto, S. Asymmetric Synthesis of Neolignans (-)-epi-Conocarpan and (+)Conocarpan via $\mathrm{Rh}$ (II)-Catalyzed $\mathrm{C}-\mathrm{H}$ Insertion Process and Revision of the Absolute Configuration of (-)-epi-Conocarpan. J. Org. Chem. 2009, 74, $4418-4421$

(12) For selected examples of stereoselective inside-type intramolecular $\mathrm{C}$ $\mathrm{H}$ insertions for syntheses of $\alpha$-aryl- $\beta, \beta$-disubstituted $\gamma$-lactones, see: (a) Doyle, M. P.; May, E. J. Enantioselective $\beta$-Lactone Formation from Phenyldiazoacetates via Catalytic Intramolecular Carbon-Hydrogen Insertion. Synlett 2001, 967-969. (b) Villalobos, M. N.; Wood, J. L. Spirolactone Syntheses through a Rhodium-Catalyzed Intramolecular C-H Insertion Reaction: Model Studies towards the Synthesis of Syringolides. Tetrahedron Lett. 2009, 50, 6450-6453.

(13) Fu, L.; Wang, H.; Davies, H. M. L. Role of Ortho-Substituents on Rhodium-Catalyzed Asymmetric Synthesis of $\beta$-Lactones by Intramolecular CH Insertions of Aryldiazoacetates. Org. Lett. 2014, 16, 3036-3039.

(14) (a) He, S.; Zeng, K.-W.; Jiang, Y.; Tu, P.-F. Nitric Oxide Inhibitory Constituents from the Barks of Cinnamomum cassia. Fitoterapia 2016, 112, 153-160. (b) Itokawa, H.; Ibraheim, Z. Z.; Qiao, Y. F.; Takeya, K. Anthraquinone, Naphthohydroqinones and naphthohydroquinone Dimers from Rubia cordifolia and Their Cytotoxic Activity. Chem. Pharm. Bull. 1993, 41, 1869-1872. (c) Lumb, J.-P.; Choong, K. C.; Trauner, D. ortho-Quinone Methides from para-Quinones: Total Synthesis of Rubioncolin B. J. Am. Chem. Soc. 2008, 130, 9230-9231. (d) Ma, S.-S.; Mei, W.-L.; Guo, Z.-K.; Liu, S.-B.; Zhao, Y.-X.; Yang, D.-L.; Zeng, Y.-B.; Jiang, B.; Dai, H.-F. Two 
New Types of Bisindole Alkaloid from Trigonostemon lutescens. Org. Lett. 2013, 15, 1492-1945.

(15) For the isolation of 13, see: (a) Liu, C.; Zhong, S.-M.; Chen, R.-Y.; Wu, Y.; Zhu, X.-J. Two New Compounds from the Dried Tender Stems of Cinnamomum cassia. J. Asian. Nat. Prod. Res. 2009, 11, 845-849. For the asymmetric total synthesis of 13, see: (b) Chen, J.-P.; Ding, C.-H.; Liu, W.; Hou, X.-L.; Dai, L.-X. Palladium-Catalyzed Regio-, Diastereo-, and Enantioselective Allylic Alkylation of Acylsilanes with Monosubstituted Allyl Substrates. J. Am. Chem. Soc. 2010, 132, 15493-15495.

(16) Liu, X.; Fu, J.; Yao, X.-J.; Yang, J.; Liu, L.; Xie, T.-G.; Jiang, P.-C.; Jiang, Z.-H.; Zhu, G.-Y. Phenolic Constituents Isolated from the Twigs of Cinnamomum cassia and Their Potential Neuroprotective Effects. J. Nat. Prod. 2018, 81, 1333-1342.

(17) Kim, G. J.; Lee, J. Y.; Choi, H. G.; Kim, S. Y.; Kim, E.; Shim, S. H.; Nam, J.-W.; Kim, S.-H.; Choi, H. Cinnamomulactone, a New Butyrolactone from the Twigs of Cinnamomum cassia and its Inhibitory Activity of Matrix Metalloproteinases. Arch. Pharmacal Res. 2017, 40, 304-310.

(18) The X-ray data for $\mathbf{2} \mathbf{b}$ has been deposited at the Cambridge Crystallographic Data Center under reference number CCDC 1839246.

(19) For a typical example of a $D_{2}$-symmetric dirhodium(II) tetracarboxylate catalyst, see: Liao, K.; Negretti, S.; Musaev, D. G.; Bacsa, J.; Davies, H. M. L. Site-Selective and Stereoselective Functionalization of Unactivated CH Bonds. Nature 2016, 533, 230-234.

(20) The X-ray data for $\mathbf{1 0}$ has been deposited at the Cambridge Crystallographic Data Center under reference number CCDC 1837271.

(21) DFT calculations on $(S)$-10 indicated that the $D_{2}$ (up-down-up-down)symmetric structure was more stable than the other possible $C_{1}$ (up-up-updown)-, $C_{2}$ (up-up-down-down)-, and $C_{4}$ (all up)-symmetric structures. For details, see the SI.

(22) It is noteworthy that the molecular symmetry changes from $C_{2}$ to $D_{2}$ from $\mathbf{2 a}$ to $\mathbf{2 b}$ and $\mathbf{1 0}$. At present, we do not have a clear explanation for this change in symmetry. However, in the cases of $\mathbf{2} \mathbf{b}$ and $\mathbf{1 0}$, close contacts between the fluorine atoms of the trifluoroacetamide groups on different ligands were observed (cf. SI). These contacts might also act as conformational locks in the $D_{2}$-symmetryic structures. An example of fluorine-fluorine close contact, see: Rusek, M.; Kwasna, K.; Budzianowski, A.; Katrusiak, A. Fluorine...Fluorine Interactions in a High-Pressure Layered Phase of Perfluorobenzene. J. Phys. Chem. C2020, 124, 99-106.

(23) Davies, H. M. L.; Bruzinski, P. R.; Lake, D. H.; Kong, N.; Fall, M. J. Asymmetric Cyclopropanations by Rhodium(II) $\mathrm{N}$-(Arylsulfonyl)prolinate Catalyzed Decomposition of Vinyldiazomethanes in the Presence of Alkenes. Practical Enantioselective Synthesis of the Four Stereoisomers of 2-Phenylcyclopropan-1-amino Acid. J. Am. Chem. Soc. 1996, 118, 6897-6907.

(24) Watanabe, N.; Ogawa, Y.; Ohtake, S.; Ikegami, S.; Hashimoto, S. Dirhodium(II) Tetrakis[ $N$-phthaloyl-( $S)$-tert-leucinate]: A Notable Catalyst for Enantiotopically Selective Aromatic Substitution Reactions of $\alpha$-Diazocarbonyl Coumounds. Amidation of C-H Bonds. Synlett 1996, 85-86.

(25) Yamawaki, M.; Tsutsui, H.; Kitagaki, S.; Anada, M.; Hashimoto, S. Dirhodium(II) Tetrakis[ $N$-tetrachlorophthaloyl- $(S)$-tert-leucinate]: a New Chiral Rh(II) Catalyst for Enantioselective Amidation of C-H Bonds. Tetrahedron Lett. 2002, 43, 9561-9564.

(26) Müller, P.; Allenbach, Y.; Robert, E. Rhodium(II)-Catalyzed Olefin Cyclopropanation with the Phenyliodonium Ylide Derived from Meldrum's Acid. Tetrahedron: Asymmetry 2003, 14, 779-785.

(27) Qin, C.; Boyarskikh, V.; Hansen, J. H.; Hardcastle, K. I.; Musaev D. G.; Davies, H. M. L. $D_{2}$-Symmetric Dirhodium Catalyst Derived from a 1,2,2Triarylcyclopropanecarboxylate Ligand: Design, Synthesis and Application. J. Am. Chem. Soc. 2011, 133, 19198-19204.

(28) Doyle, M. P.; Bagheri, V.; Wandless, T. J.; Harn, N. K.; Brinker, D. A.; Eagle, C. T.; Loh, K. L. Exceptionally High Trans (Anti) Stereoselectivity in Catalytic Cyclopropanation Reactions. J. Am. Chem. Soc. 1990, 112, 1906 1912.

(29) Hikichi, K.; Kitagaki, S.; Anada, M.; Nakamura, S.; Nakajima, M.; Shiro, M.; Hashimoto, S. Synthesis and Evaluation of Novel Dirhodium(II)
Carboxylate Catalysts with Atropisomeric Biaryl Backbone. Heterocycles 2003, 61, 391-401.

(30) The $E / Z$-mixture of the olefin dimer of $11 \mathrm{a}$ and the hydroxylated product were generated as the main side products. For the chemical yields of these compounds, see the SI.

(31) Berova, N. D.; Kurtev, B. J. Absolute Configurations of Some 1,2-Diphenylethane Derivatives. Tetrahedron 1969, 25, 2301-2311. 